\title{
Blockade of Glutamatergic Transmission in Perirhinal Cortex Impairs Object Recognition Memory in Macaques
}

\author{
Ludise Malkova, ${ }^{1}$ Patrick A. Forcelli, ${ }^{1}$ Laurie L. Wellman, ${ }^{2}$ David Dybdal, ${ }^{1}$ Mark F. Dubach, ${ }^{2}$ and Karen Gale ${ }^{\dagger}$ \\ ${ }^{1}$ Department of Pharmacology and Physiology, Georgetown University Medical Center, Washington DC 20007 and ${ }^{2}$ Department of Psychiatry and \\ Behavioral Sciences, University of Washington, Seattle, Washington 98195
}

\begin{abstract}
The perirhinal cortex $(\mathrm{PRc})$ is essential for visual recognition memory, as shown by electrophysiological recordings and lesion studies in a variety of species. However, relatively little is known about the functional contributions of perirhinal subregions. Here we used a systematic mapping approach to identify the critical subregions of PRc through transient, focal blockade of glutamate receptors by intracerebral infusion of kynurenic acid. Nine macaques were tested for visual recognition memory using the delayed nonmatch-tosample task. We found that inactivation of medial PRc (consisting of Area 35 together with the medial portion of Area 36), but not lateral PRc (the lateral portion of Area 36), resulted in a significant delay-dependent impairment. Significant impairment was observed with 30 and $60 \mathrm{~s}$ delays but not with $10 \mathrm{~s}$ delays. The magnitude of impairment fell within the range previously reported after PRc lesions. Furthermore, we identified a restricted area located within the most anterior part of medial PRc as critical for this effect. Moreover, we found that focal blockade of either NMDA receptors by the receptor-specific antagonist AP-7 or AMPA receptors by the receptor-specific antagonist NBQX was sufficient to disrupt object recognition memory. The present study expands the knowledge of the role of PRc in recognition memory by identifying a subregion within this area that is critical for this function. Our results also indicate that, like in the rodent, both NMDA and AMPA-mediated transmission contributes to object recognition memory.
\end{abstract}

Key words: AP-7; glutamate antagonist; kynurenate; medial temporal; NBQX; pigtail macaque

\section{Introduction}

Visual object recognition memory refers to the ability to determine whether an object has been previously seen. This form of memory critically relies on the perirhinal cortex (PRc), located in the inferior medial temporal lobe. The importance of PRc for this function has been demonstrated through experiments using aspiration and excitotoxic lesions in nonhuman primates (ZolaMorgan et al., 1989; Meunier et al., 1993; Suzuki et al., 1993; Murray et al., 1996; Buffalo et al., 1999, 2000; Baxter and Murray, 2001; Málková et al., 2001; Rauchs et al., 2006) and rats (Bussey et al., 2000; Winters et al., 2004; Abe et al., 2009; Albasser et al., 2009), electrophysiological recordings in nonhuman primates (Miller et al., 1991; Li et al., 1993), neuroimaging in nonhuman primates and humans (Blaizot et al., 2000; Buffalo et al., 2006; Bellgowan et al., 2009; Miyamoto et al., 2014), and pharmacological inactivation in rats (Abe et al., 2004; Winters and Bussey, 2005a, b).

\footnotetext{
Received 0ct. 17, 2014; revised Jan. 20, 2015; accepted Feb. 15, 2015.

Author contributions: L.M., M.F.D., and K.G. designed research; L.M., L.L.W., D.D., M.F.D., and K.G. performed research; L.M., P.A.F., L.L.W., D.D., and K.G. analyzed data; L.M., P.A.F., and K.G. wrote the paper.

The study was supported by R01 01458004 to K.G. and K02 HD42269 to L.M. We thank Laura Williams, Michael Oppedisano, Ivy Eastabrook, Kenita Barrow, Danielle Zierath, and Virginia Gunderson for assistance with these studies.

The authors declare no competing financial interests.

${ }^{\dagger}$ Deceased, August 21, 2014.

Correspondence should be addressed to Ludise Malkova, PhD, Department of Pharmacology and Physiology, Georgetown University, Washington DC 20007. E-mail: malkova@@georgetown.edu.

DOI:10.1523/JNEUROSCI.4307-14.2015

Copyright $\odot 2015$ the authors $\quad 0270-6474 / 15 / 355043-08 \$ 15.00 / 0$
}

Despite the wealth of data documenting the importance of $\mathrm{PRc}$ for the mnemonic processes underlying object recognition memory, relatively little is known about the role of perirhinal subregions. PRc is not a homogenous structure; it is divided into two cytoarchitectonically and chemoarchitectonically distinct subregions, Areas 35 and 36 (Fig. 1). These neighboring regions also differ with respect to anatomical connections (Lavenex et al., 2002, 2004; Suzuki and Amaral, 2003; Saleem et al., 2007). Area 35 (located medially), compared with Area 36, receives heavier input from the orbitofrontal (Area 12; Van Hoesen et al., 1975), anterior cingulate (Bunce and Barbas, 2011; Bunce et al., 2013), and dysgranular insular cortices (Mesulam and Mufson, 1982; Friedman et al., 1986). In contrast, Area 36 receives heavier input from posterior orbitofrontal regions (Area 13; Kondo et al., 2005; Bunce and Barbas, 2011; Bunce et al., 2013) and stronger input from inferotemporal cortical areas TF, TE, TEav, and TEo. On the basis of these anatomical differences, we hypothesized that these two areas contribute to object recognition memory in a different manner.

While prior studies using lesion approaches have demonstrated that damage to PRc disrupts object recognition memory, the interpretation of these results may be compromised by longterm compensatory adaptation occurring in the days and weeks after lesions (Webster et al., 1995; Fox et al., 2010; O’Reilly et al., 2013). Indeed, the fact that performance on object recognition tasks was maintained significantly above chance levels in all previous PRc lesion studies (see Discussion) suggests that in the postlesion period subjects may have learned to resolve the task by 
developing a strategy distinct from that used in the presence of an intact PRc.

Rapid and reversible inactivation of a brain region by focal intracerebral drug infusions (e.g., with drugs that block glutamatergic neurotransmission or enhance GABAergic neurotransmission) is a technique that enables us to both explore perirhinal subregions on a within-subject basis and avoid compensatory adaptations. Because there is no opportunity for the compensatory adaptation, the acute disruption of neural transmission may yield more severe impairment and/or a different mode of impairment than permanent lesions. This approach also enables us to probe the contribution of specific neurotransmitter receptor systems. In the rat, it has been shown that AMPA receptor activation is necessary for performance on the delayed nonmatchto-sample task (DNMS) using both short and long delays, whereas NMDA receptor activation is only necessary for recall at long delays (Abe et al., 2004; Winters and Bussey, 2005a; Warburton et al., 2013). However, the role of these receptor subtypes in object recognition in macaques is unknown.

Here we used a systematic mapping approach to identify the critical subregions within PRc for object recognition memory, assessed by DNMS, using focal microinfusions of glutamate receptor antagonists in PRc in macaques.

\section{Materials and Methods}

Subjects. Nine pigtail macaques (Macaca nemestrina), six females (KZ, MJ, DE, KI, JV, and $\mathrm{OH}$ ) and three males (KM, MI, and OK), were used in this study. They were born and raised at the Infant Primate Research Laboratory at the University of Washington Regional Primate Research Facility. Five animals (KM, KZ, MJ, MI, and DE) started behavioral training and testing at the age of 1.5-2 years and completed all experiments at the University of Washington. In addition to the drug infusions in perirhinal cortex that these animals received in the present experiment, they received infusions in the piriform cortex for another experiment that will be published separately. Four animals (KI, OK, OH, and JV) were transferred to Georgetown University and all experimental procedures in these animals were conducted at Georgetown University. The latter four animals were 2-4 years old at the beginning of the study and were experimentally naive.

Care and housing of the monkeys at the University of Washington Regional Primate Research Center and at the Georgetown University Research Resource Animal Facility met or exceeded the standards as stated in the Guide for Care and Use of Laboratory Animals (National Research Council, 2011), Institute for Laboratory Animal Research recommendations and Association for Assessment and Accreditation of Laboratory Animal Care accreditation standards. The study was conducted under protocols approved by the Institutional Animal Care and Use Committees both at the University of Washington Research Center and at Georgetown University.

Apparatus and materials. Training and testing were conducted in a Wisconsin General Testing Apparatus inside a darkened, sound-shielded room as previously described (Málková et al., 2001). The stimuli consisted of $\sim 500$ different junk objects, approximating a "trial unique"
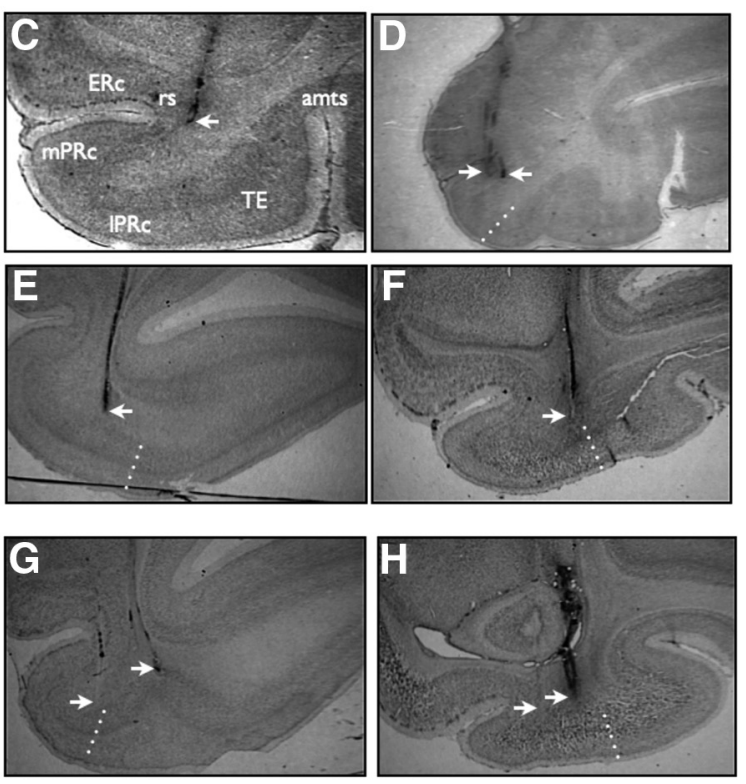

Figure 1. Infusion sites. $\boldsymbol{A}$, Intended area of infusions shown on coronal sections from a standard rhesus macaque brain atlas of the perirhinal cortex in dark gray. $\boldsymbol{B}$, MRI image from a single subject. Arrow indicates the location of the rhinal sulcus 政

stimulus set, i.e., each object was used no more than once in an experimental session. Typically, 50 objects were used in an experimental session, thus, the same objects were not presented again for $\sim 10$ experimental sessions. The stimuli varied widely in color, shape, size, and texture.

Behavioral training and testing. After learning by approximation to displace objects from baited wells, the animals were taught the rule for DNMS. Each trial consisted of a study phase, in which a baited sample object was presented over the central well. After the animal displaced the object, the divider between the monkey and the objects was closed for a 10 s delay. After the delay, a retention test was conducted in which a baited novel object and the sample object (now unbaited) were paired. The positions of the novel object and sample object varied between the left and right wells in a pseudorandom order. An intertrial interval of $30 \mathrm{~s}$ separated consecutive trials. For each trial, a new pair of objects was drawn. Training continued in sessions of 25 trials per day until the animals reached a criterion of 90 (or more) correct choices in 100 consecutive trials (i.e., over $4 \mathrm{~d}$ ). After reaching criterion at the $10 \mathrm{~s}$ delay, the delay between the sample presentation and the choice test was gradually increased to $30 \mathrm{~s}$, and subsequently, $60 \mathrm{~s}$, allowing the monkeys to reach criterion on each. Finally, all delays were mixed within an experimental session in a pseudorandomized order and the animals were retrained to criterion. Upon reaching criterion, each animal was implanted with an infusion chamber for intracerebral drug infusions (see below).

During the postoperative experimental phase, baseline testing sessions with no drug infusions were intermixed with experimental testing sessions. Testing sessions included infusions of saline, kynurenic acid (KYNA), NBQX, or AP-7 before the DNMS test. Baseline DNMS sessions were performed $24 \mathrm{~h}$ before drug infusions. The order of treatments for each experimental condition was randomized across animals. The minimum planned session duration was 24 trials, during which each of the three delays was equally represented and distributed pseudorandomly 
Table 1. Number of infusions per subject for each experimental condition

\begin{tabular}{|c|c|c|c|c|c|c|c|c|c|}
\hline & SAL & $\begin{array}{l}\text { Medial, anterior, } \\
\text { bilateral } \\
\text { Three } \\
\text { KYNA }\end{array}$ & $\begin{array}{l}\text { Medial, anterior, } \\
\text { bilateral } \\
\text { Two } \\
\text { KYNA }\end{array}$ & $\begin{array}{l}\text { Medial, anterior, } \\
\text { bilateral } \\
\text { Two } \\
\text { AP7 }\end{array}$ & $\begin{array}{l}\text { Medial, anterior, } \\
\text { bilateral } \\
\text { Two } \\
\text { NBQX }\end{array}$ & $\begin{array}{l}\text { Medial, anterior, } \\
\text { bilateral } \\
\text { One } \\
\text { KYNA }\end{array}$ & $\begin{array}{l}\text { Medial, anterior, } \\
\text { unilateral } \\
\text { Three } \\
\text { KYNA }\end{array}$ & $\begin{array}{l}\text { Medial, posterior, } \\
\text { bilateral } \\
\text { Three } \\
\text { KYNA }\end{array}$ & $\begin{array}{l}\text { Lateral, anterior, } \\
\text { bilateral } \\
\text { Three } \\
\text { KYNA }\end{array}$ \\
\hline KZ $\square$ & 1 & 2 & 4 & - & - & 1 & 1 & 1 & 1 \\
\hline MJ $\Delta$ & 1 & 2 & - & - & - & 1 & 2 & 4 & 1 \\
\hline MI $\nabla$ & 1 & 2 & 1 & - & - & 2 & 1 & - & 1 \\
\hline OK॰ & 2 & - & 2 & 2 & 2 & - & - & - & - \\
\hline $\mathrm{OH} \odot$ & 4 & - & 4 & 1 & 3 & - & - & - & - \\
\hline $\mathrm{JV} \odot$ & 1 & - & 6 & 3 & - & - & - & - & - \\
\hline
\end{tabular}

SAL, saline.

within session. In some cases, when the animal was cooperative, they were tested on additional trials (up to 50).

Cranial infusion platform and injector. The cranial platform was made of acrylic and was constructed and implanted under aseptic conditions as described in detail in our previous publications (Wellman et al., 2005; Dybdal et al., 2013). For each drug infusion, a cannula (27 gauge) was inserted through the platform using a custom-built telescoping injector (Elmeco Engineering; Wellman et al., 2005), which fitted snugly into the infusion platform and allowed an easy adjustment of the cannula length. The infusion platform permitted injections spaced at $2 \mathrm{~mm}$ intervals in the anteroposterior and mediolateral planes, with submillimeter resolution in the dorsoventral plane.

Magnetic resonance imaging. Postoperatively, each monkey received at least one T1-weighted scan to determine and/or verify the coordinates for the infusion sites. Additional scans were performed throughout the experiment as needed. Scans were conducted as previously described (Dybdal et al., 2013) with an effective resolution of $1.0 \times 1.0 \times 1.0 \mathrm{~mm}^{3}$. To verify the location of the predetermined infusion sites, tungsten microelectrodes (FHC) were inserted through the infusion grid. The tip of the electrode was placed $\sim 10 \mathrm{~mm}$ above the intended site and visualized on the MRI scan (Holmes et al., 2012; DesJardin et al., 2013; Forcelli et al., 2014). Based on the position of the tip of the electrode on the MRI scan, the final coordinates for the drug infusions were adjusted with respect to the coordinates of the infusion platform. For some animals, the infusion sites were also verified by focal infusion of the MR contrast agent gadolinium $(1.5 \mu \mathrm{l}, 5 \mathrm{~mm}$ ) using the technique as previously described (Wilke et al., 2010; Holmes et al., 2012; DesJardin et al., 2013). As shown in Figure $1 B$, the contrast agent generated hypersignal visible in a $3-4 \mathrm{~mm}$ region of diffusion confined to PRc.

Drug solutions. The following drugs were used to block neural transmission in PRc: KYNA, a broad-spectrum glutamate receptor antagonist (RBI); AP-7, an NMDA receptor-specific antagonist (RBI); and NBQX (Sigma), an AMPA receptor-specific antagonist. KYNA and NBQX (as the disodium salt) were each dissolved in a small volume of dilute $\mathrm{NaOH}$, neutralized with dilute $\mathrm{HCl}$, and adjusted to final concentration by the addition of sterile water. The final concentration of KYNA was $300 \mathrm{~mm}$ and the final concentration of NBQX was $20 \mathrm{~mm}$. AP-7 was dissolved in sterile saline at a final concentration of $50 \mathrm{~mm}$. All drug solutions were filtered $\left(20 \mu \mathrm{m}\right.$ pore size) before storing as $1 \mathrm{ml}$ frozen aliquots $\left(-20^{\circ} \mathrm{C}\right)$.

Doses used per infusion site were as follows: kynurenate $(600 \mathrm{nmol}$ in $2 \mu \mathrm{l})$, NBQX (20 nmol in $1 \mu \mathrm{l})$, and AP-7 (100 nmol in $2 \mu \mathrm{l})$. The infusion volume (1-2 $\mu$ l per site) produces a diameter of inactivation covering at least 3-4 mm. The dose and volume for KYNA was based on the effective dose used in our previous experiments with infusions of this drug in the hippocampus (Forcelli et al., 2014). The dose and volume for AP-7 and NBQX were based on our experience using these compounds in other brain regions in the primate, and are within the range of concentrations previously used in the rat perirhinal cortex (Abe et al., 2004; Winters and Bussey, 2005a). Even at high concentrations, NBQX and AP-7 selectively target AMPA and NMDA receptors, respectively.

Targeting sites within PRc. Drug infusions were aimed at PRc using the cytoarchitectonic borders as defined previously (Saleem et al., 2007; Fig.
1A). We divided the PRc in two regions, medial and lateral. The intended medial PRc sites included the lateral half of the fundus and the lateral bank of the rhinal sulcus, encompassing Area 35 and the medial portion of Area 36. The lateral PRc sites targeted the lateral portion of Area 36, i.e., the tissue between the lateral lip of the rhinal sulcus and, laterally, the border with TE. To determine the border with Area TE (von Bonin and Bailey, 1947), we were guided by the definition by Saleem et al. (2007) compared with anatomical study by Suzuki and Amaral (1994), which places at the PRc border with TE more laterally. Based on Saleem et al. (2007) and also consistent with the borders used by Davachi and Goldman-Rakic (2001), we placed the lateral border of PRc at the midpoint between the lateral lip of the rhinal sulcus and the medial lip of the anterior middle temporal sulcus (amts) in the more posterior sections, in which the amts was present. For the anterior sections, rostral to the amts, we placed the lateral border of PRc at the third of the distance between the lateral lip of the rhinal sulcus and the medial lip of the superior temporal sulcus.

Drug infusions. Drug infusions were conducted, as previously described (Dybdal et al., 2013), using sterile technique in the awake/behaving monkey while the animal was seated in a primate chair (Crist Instruments). Drugs (as sterile solutions) were infused at a rate of $1 \mu \mathrm{l} / 10$ min using a Hamilton syringe driven by an infusion pump. As described above, for bilateral infusions, two to three infusion sites were used per hemisphere, and for unilateral infusions, there were three sites per hemisphere. The sites were spaced $2 \mathrm{~mm}$ apart, which was permitted by the infusion grid. With the effective drug spread, we aimed to inactivate an area of $\sim 6-8 \mathrm{~mm}$ in the rostrocaudal extent and $3 \mathrm{~mm}$ at the mediolateral extent. At least $3 \mathrm{~d}$ elapsed between drug treatments in an individual subject.

Infusions were aimed at the rostral half of the PRc. As shown in Figure $1 A$, the most rostral site was intended to target rostral perirhinal cortex, approximately at the level +18 (with respect to the interaural plane; Fig. $1 A)$. In the first five experimental animals (KM, KZ, MJ, MI, and DE), three sites $(+18,+16$, and +14 ; Fig. $1 A)$ were used per hemisphere, spaced $2 \mathrm{~mm}$ apart in the rostrocaudal extent. In the remaining four animals, similar behavioral effect was achieved with two most rostral sites $(+18$ and +16 ; Fig. 1A) per hemisphere and thus only these two sites were used throughout the experiments for these animals.

All monkeys received bilateral injections of KYNA in medial PRc and at least one saline infusion at the same site. Each animal received additional infusions, which consisted of one or two of the following options: unilateral KYNA injections in medial PRc, bilateral KYNA infusions in lateral PRc, bilateral infusions of NBQX, and bilateral infusions of AP-7. The injections of NBQX and AP-7 were aimed at medial PRc. The order of experimental conditions was randomized across animals. The number of injections in each animal is presented in Table 1.

To evaluate site specificity within the rostrocaudal axis of the PRc, a subset of animals also received three infusions positioned $2 \mathrm{~mm}$ caudally to the rostral site (i.e., $+16,+14,+12$; Fig. $1 A$ ). To evaluate the rostrocaudal volume of inactivation necessary to induce behavioral deficits, a subset of animals was tested with one, two, or three infusions positioned along the rostrocaudal axis. In these experiments, the rostral-most site 
A
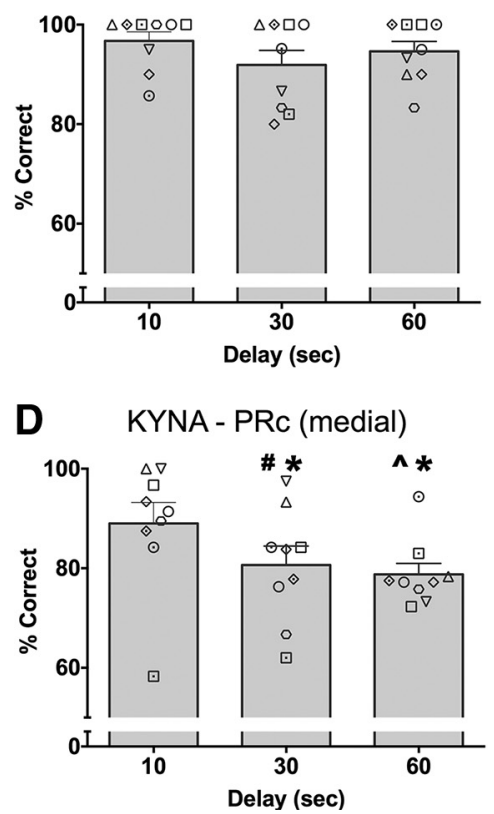

B KYNA- PRc (lateral)

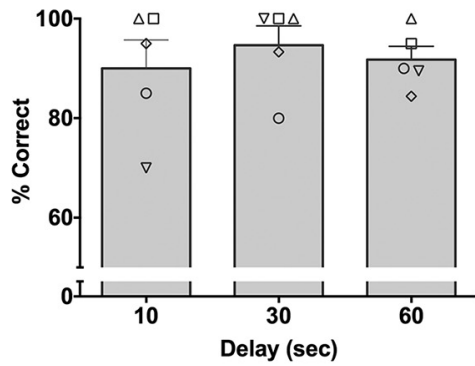

E NBQX - PRc (medial)

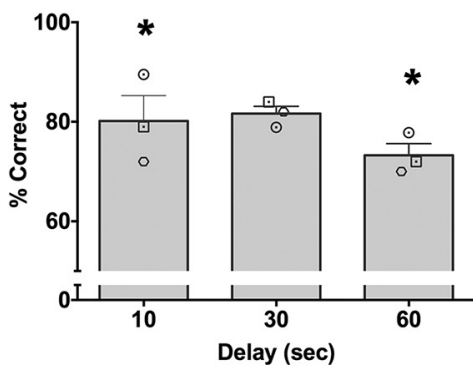

C KYNA-PRc (unilateral)
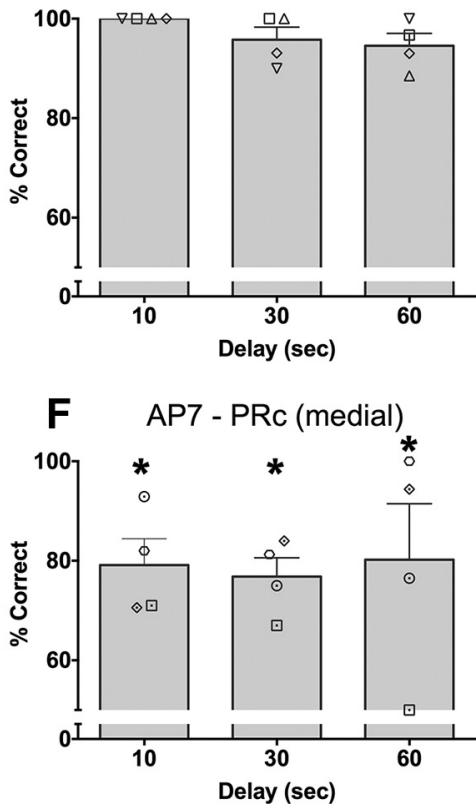

Figure 2. Performance (as measured by percentage correct trials) as a function of delay. Conditions: saline infusion (A), bilateral infusion of KYNA into the lateral PRc ( $\boldsymbol{B})$, unilateral infusion of KYNA into the medial PRc $(\boldsymbol{C})$, bilateral infusion of KYNA into the medial PRc $(\boldsymbol{D})$, bilateral infusion of NBQX into the medial PRc $(\boldsymbol{E})$, and bilateral infusion of AP-7 into the medial PRc $(\boldsymbol{F})$. ${ }^{*} p<0.05$ indicates significantly different from the saline-infused condition and $\wedge p<0.05$ indicates significantly different from performance under 10 s delays within a given condition. Bars represent means (+SEM). Open symbols overlaid on the bar graphs represent individual monkeys and correspond to those used in Table 1.

$(+18)$ was held constant and additional sites positioned caudally in 2 $\mathrm{mm}$ increments were added to it (i.e., +16 , for the two-infusion session or +16 , and +14 , for the three-infusion session).

Infusion sites, determined from the MRI scan for each monkey, were confirmed by histological evaluation for all cases, following the technique as previously described (West et al., 2011; Holmes et al., 2012; Forcelli et al., 2014). Some tracks evident in histology arose from infusions stereotaxically targeting area TE (Fig. 1G; the lateral track). However, data generated from those infusions were not included in the present analyses and those tracks were disregarded. Examples of targets in medial PRc are shown in Figure 1,C and $D$, and medial tracks in $G$ and $H$. Some infusions were placed in the fundus of the rhinal sulcus (Fig. 1C) and thus possibly affected the lateral-most portion of the entorhinal cortex. Examples of lateral infusions are shown in Figure 1, $E$ and $F$, and lateral track in $H$. In some cases, the lateral infusions were placed close to the lateral border of PRc (Fig. 1F) and, thus, likely encroached on medial TE.

Data analysis. Data were analyzed using SPSS (IBM) and Prism (GraphPad) software. A linear mixed model was used with subject (monkey) as a random effect. This model was used due to the unbalanced design, i.e., not every monkey received every treatment. In this model, delay (10 s, $30 \mathrm{~s}$, or $60 \mathrm{~s})$ was used as a repeated measure within each level of treatment type (saline, bilateral KYNA in medial PRc, unilateral KYNA in medial PRc, bilateral KYNA in lateral PRc, NBQX in medial PRc, or AP-7 in medial PRc). Based on Akaike Information Criteria, the model was not improved by adding treatment or delay as independent terms, nor by adding a delay by treatment term. After the omnibus analysis (above), we compared performance across delays for each treatment separately and we also compared performance across treatments for each delay. For the site specificity experiments, within-subject ANOVA was applied using subsets of animals that were tested under all experimental conditions of interest. Post hoc analyses (Bonferroni-Holm corrected) and planned comparisons were performed when appropriate. The threshold for statistical significance was set at $p<0.05$.

\section{Results}

\section{Baseline performance}

Animals were trained on the DNMS until stable baseline performance was reached, with $90 \%$ accuracy at all delays. The average number of sessions to reach this criterion was 32 (range 23-45). After reaching criterion, animals began microinfusion experiments. Saline infusions are presented as a control (Fig. $2 A$ ). After saline microinfusion, animals performed at a high level; performance was significantly $>85 \%$ on all delays (one-sample $t$ test; $t=6.51$, df $8, p<0.005 ; t=2.36$, df $8, p<0.05 ; t=4.81$, df $=8$, $p<0.005$ for the 10,30 , and 60 s delays, respectively). Consistent with this, performance did not differ across delays $\left(F_{(2,75.9)}=\right.$ $0.71, p=0.50)$.

\section{The effects of glutamatergic blockade within PRc on DNMS performance}

Mixed-effects analysis, which included all types of treatments shown in Figure 2, revealed a significant main effect of delay within treatment $\left(F_{(17,76.5)}=3.36, p<0.0005\right)$. Subsequent analyses performed for each treatment showed that the effect of delay was significant only for the KYNA in medial PRc condition $\left(F_{(2,75.9)}=3.5, p<0.05\right)$ but not for any other condition. We next analyzed the simple effect of treatment within each level of delay and found significant treatment effects at each level of delay: 10 $\left(F_{(5,8)}=3.25, p<0.01\right), 30\left(F_{(5,8)}=3.41, p<0.01\right)$, and $60 \mathrm{~s}$ $\left(F_{(5,8)}=4.86, p<0.001\right)$. This result, indicating treatment differences at each delay level, is further decomposed below.

\section{Region and delay-dependent effects of KYNA}

Bilateral KYNA infusions aimed at medial PRc (Fig. 2B) significantly impaired object recognition. This impairment was delay dependent as evident by the finding that performance on $10 \mathrm{~s}$ delay trials was not different from that following saline infusion, 


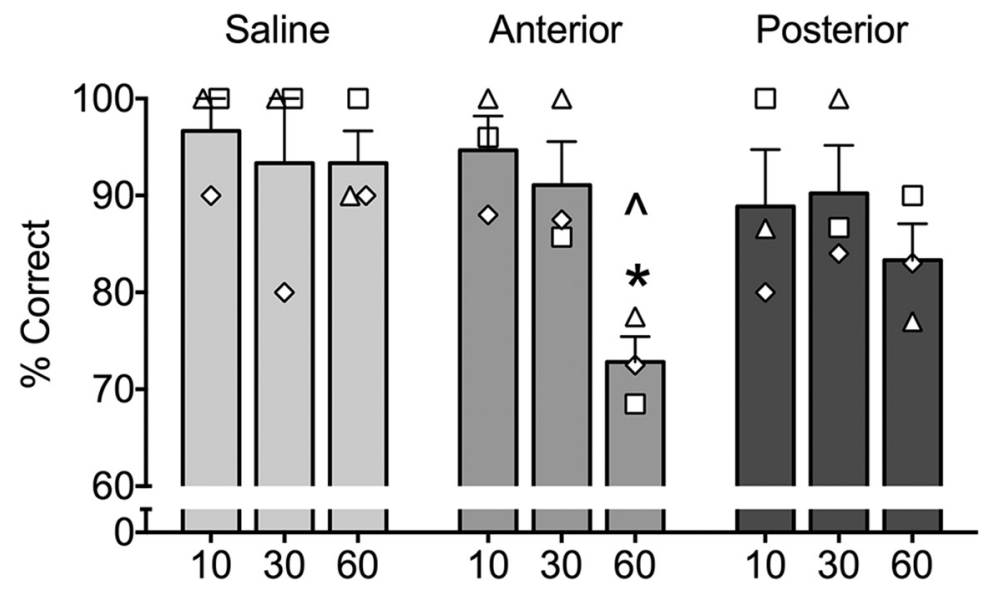

Figure 3. Effect of rostrocaudal position within PRc on memory impairment induced by kynurenic acid (KYNA). Performance (as measured by percentage correct trials) as a function of delay (10,30, and 60 represent individual delays in seconds). Anterior condition targeted infusions to the medial PRc at levels $+18,+16$, and +14 from the interaural line as outlined in Figure 1 . Posterior condition targeted infusions to the medial PRc at levels $+16,+14$, and +12 . * indicates significantly different from 10 $\mathrm{s}$ and $^{\wedge}$ indicates significantly different from the equivalent delay under saline-infused conditions. Bars represent means ( + SEM). Open symbols overlaid on the bar graphs represent individual monkeys and correspond to those used in Table 1.

30 , and $\left.60 \mathrm{~s} ; F_{(4,16)}=4.79, p<0.01\right)$ and significant main effect of delay $\left(F_{(2,8)}=\right.$ $6.63, p=0.02)$ but no main effect of treatment $\left(F_{(2,8)}=3.66, p=0.08\right)$. Post hoc analysis showed no difference in performance between the sites on 10 and 30 s delays but a significant difference on $60 \mathrm{~s}$ delay. On the $60 \mathrm{~s}$ delay, the performance after infusions in medial PRs was significantly lower than that following infusions in lateral PRc $(p<$ $0.003)$ and saline $(p<0.001)$, whereas the latter two did not differ from each other.

\section{Effect of rostrocaudal position of infusions on memory impairment}

First, we aimed to determine whether moving the infusion sites in the caudal direction would change the effect of glutamate transmission blockade in the medial PRc. In three of the subjects that received three infusions per hemisphere (KZ, MJ, and $\mathrm{DE}$ ), we moved the three infusion sites $2 \mathrm{~mm}$ caudally, i.e., the extent of the

whereas performance on both 30 and 60 s delay trials was significantly lower than that after saline $(p<0.05$, Bonferroni-Holms correct post hoc test). In addition, post hoc tests following the significant effect of delay reported above revealed that, after KYNA in medial PRc, performance was significantly lower on the $60 \mathrm{~s}$ delay than on the $10 \mathrm{~s}$ delay $(p<0.05)$ and the difference between the performance on the $30 \mathrm{~s}$ delay versus the $10 \mathrm{~s}$ delay just fell short of significance $(p=0.053)$.

In contrast to the bilateral infusions, unilateral KYNA infusions aimed at medial PRc had no effect on performance on any delay (Fig. $2 D$; $p s>0.05$, compared with saline). Moreover, there was no significant effect of delay in this condition $\left(F_{(2,75.9)}=0.44\right.$, $p=0.65)$. Within-subject ANOVA with repeated measures performed on a subset of three animals, which received both bilateral and unilateral infusions (in separate sessions), confirmed this effect. The analysis revealed a significant interaction between treatment (bilateral, unilateral, and saline) and delay (10, 30, and $\left.60 \mathrm{~s} ; F_{(4,12)}=7.28, p<0.004\right)$ and significant main effects of delay $\left(F_{(2,6)}=12.96, p<0.007\right)$ and treatment $\left(F_{(2,8)}=6.52, p<0.04\right)$. Post hoc analysis indicated no differences between treatments on 10 and 30 s delays but significant differences on 60 s delay, where the performance after bilateral infusions in medial PRc was significantly lower than that following unilateral infusions $(p<0.0001)$ and saline $(p<0.0001)$; performance after unilateral infusions was not different from saline $(p=0.96)$. This finding indicates that a unilateral blockade of glutamate transmission within medial PRc is not sufficient to impair object recognition, rather, a bilateral disruption is necessary to achieve this effect.

Similar to the unilateral infusions in medial PRc, bilateral KYNA infusions placed in the lateral PRc were without effect on performance for any of the delays (Fig. $2 C$; ps $>0.05$, compared with saline) and there was no significant effect of delay in this treatment condition $\left(F_{(2,75.9)}=0.37, p=0.70\right)$, revealing a sitespecific effect of the glutamate transmission blockade on object recognition. Within-subject ANOVA with repeated measures performed on a subset of five animals, which received both medial and lateral infusions (in separate sessions), confirmed this site specificity effect. The analysis revealed a significant interaction between treatment (medial, lateral, and saline) and delay (10, tissue inactivated by the KYNA infusions moved away from the rostral-most site in PRc $(+18,+16$, and +14$)$ toward the caudal half of PRc $(+16,+14$, and +12$)$, but with two sites overlapping. Within-subject ANOVA with repeated measures revealed a significant treatment (anterior, posterior, and saline) by delay interaction $\left(10,30\right.$, and $\left.60 s ; F_{(4,8)}=4.60, p<0.04\right)$ but no main effect of treatment or delay. Post hoc comparisons (Holm-Sidak) showed that infusions aimed at the rostral sites resulted in a significant impairment at the longest delays compared with saline $(p<0.01)$, confirming the robust effect, described above, even with the sample limited to three subjects (Fig. 3). In contrast, performance after infusions aimed at the caudal sites was not significantly different from either saline or the performance after infusions in the rostral sites. This outcome suggests that moving the sites away from the most rostral site in PRc decreases the behavioral effect of blocking the glutamate transmission.

Based on our finding that the two most anterior infusion sites were sufficient to produce an effect equal in magnitude to the effect of three sites per hemisphere, we made a systematic comparison between three sites, two sites, and a single site per hemisphere. All three experiments included the rostral-most site $(+18)$; this was the location of the infusion in the "one-site" condition. The "two-site" condition included the rostral-most site, and a second site positioned $2 \mathrm{~mm}$ caudally $(+16)$. The "three-site" condition included both of the sites in the "two-site" condition, as well as a third site, located an additional $2 \mathrm{~mm}$ caudally $(+14)$. As shown in Figure 4, all treatment types showed a delay-dependent effect with significant difference compared with saline at $60 \mathrm{~s}$ (all ps $<0.05$, one sided), while not being different from each other. These effects were revealed by ANOVA (main effect of treatment [saline vs 1 site vs 2 sites vs 3 sites], $F_{(3,20)}=5.364, p=0.007$; main effect of delay: $F_{(2,40)}=10.97$, $p=0.0002)$ with Holm-Sidak corrected post hoc tests. Thus, blockade of glutamate transmission yielded a significant disruption of memory performance even when only a single site per hemisphere was used.

Within-subject ANOVA with repeated measures performed on a subset of four animals, which received infusions both in the one-site and the three-site conditions (there were only two animals that had all three conditions precluding the inclusion of this condi- 
tion in the analysis; Table 1), confirmed this effect. The analysis revealed a significant effect of delay $\left(F_{(2,12)}=20.48, p=0.0001\right)$ but no effect of treatment $\left(F_{(1,6)}=0.034, p=\right.$ $0.86)$ or interaction between treatment and delay $\left(F_{(2,12)}=0.93, p=0.42\right)$. Together, our findings indicated that the critical tissue mediating object recognition memory is located in a relatively restricted zone within the rostral-most medial PRc.

\section{Effects of AMPA- and NMDA-specific blockade}

Microinfusion of the AMPA receptor antagonist NBQX into medial PRc yielded a significant impairment in performance, which was significant at 10 and $60 \mathrm{~s}$ delays $(p<0.05$ and $p<0.005$, respectively, compared with saline) and approached significance at the $30 \mathrm{~s}$ delay $(p=0.07$, uncorrected). There was no evidence of delay dependence in this condition $\left(F_{(2,75.9)}=0.80, p=0.45\right)$.

Similarly, microinfusion of the NMDA receptor antagonist, AP-7 into medial PRc yielded a significant impairment in performance at all delays $(p s<0.01)$. Impairment was comparable across delays, as indicated by a lack of effect of delay within this treatment $\left(F_{(2,75.9)}=0.16, p=0.85\right)$.

\section{Discussion}

Here we have shown that transient, focal inactivation of medial $\mathrm{PRc}$, but not lateral PRc, via direct infusion of the broadspectrum glutamate receptor antagonist, kynurenic acid, impaired object recognition memory in the DNMS task. Furthermore, we identified a restricted area located within the most anterior part of PRc as critical for this effect. Moving the infusion sites posteriorly diminished the effect. Finally, we have shown that focal blockade of either NMDA or AMPA receptors is sufficient to disrupt object recognition memory in macaques.

The impairment in memory we found after focal blockade of glutamatergic transmission within PRc was characterized by delay dependence; impairment was observed with 30 and 60 s delays but not with a 10 s delay. This pattern of delay-dependent impairment is consistent with that reported after permanent perirhinal lesions in monkeys made either by aspiration or by the neurotoxin ibotenic acid (Meunier et al., 1993; Buffalo et al., 1999; Málková et al., 2001) and following aspiration or excitotoxic lesions that included both the perirhinal and entorhinal cortex (Meunier et al., 1993; Baxter and Murray, 2001). We had hypothesized that focal inactivation of PRc might result in more severe performance deficits as compared with lesions. In contrast to our hypothesis, we found that the magnitude of impairment observed after focal perirhinal inactivation fell within the range previously reported after various types of rhinal lesions. The fact that, similarly to lesions, acute transient inactivation of PRc failed to drop performance to chance level suggests that compensatory adaptation does not likely explain relatively spared performance after rhinal lesions. Indeed, this provides strong evidence for the notion that other brain areas actively contribute to object recognition memory. In addition to other temporal structures, prefrontal regions likely contribute to the above-chance performance in the absence of functional PRc, especially when delays up to 2 min are used. Consistent with this, a critical con- tribution of prefrontal cortices to DNMS has been demonstrated in several lesion studies in monkeys (Kowalska et al., 1991; Meunier et al., 1997; Málková et al., 2000, 2014).

Within the PRc, we found that the critical substrate for object recognition memory was located in the anteromedial perirhinal cortex, namely Area 35 and the medial portion of Area 36. Only when infusions were aimed at this site, situated within the anterior portion of the rhinal sulcus, did we detect impairment. The notion that there might be a critical subregion within PRc was raised in a previous study using neurotoxic perirhinal lesions (Málková et al., 2001). In the aforementioned study, the extent of perirhinal damage (mean of 54\% across subjects) was substantially smaller than the extent of perirhinal damage after ablations (88\%; Meunier et al., 1993), yet the performance of the animals in both studies was equally impaired. At the time, it was suggested that anterior PRc may be critical since the rostral half of PRc sustained damage in all subjects. Further analysis of the lesions, however, also points to the critical involvement of the medial PRc since the damage in at least two cases (PI-1 and PI-4; Málková et al., 2001, their Fig. 1) was limited to the medial bank and yet yielded significant impairment. Similarly, in monkeys with rhinal ablations restricted to the anterior perirhinal and entorhinal cortices, performance was significantly impaired as compared with controls (Murray et al., 1996). Moreover, rhinal (entorhinal and perirhinal) lesions predominately targeting the anteromedial region of the PRc resulted in significant impairment in cross-modal object recognition memory (Goulet and Murray, 2001).

Involvement of this anteromedial region of perirhinal cortex in object recognition is also supported by previous studies using PET imaging in baboons (Blaizot et al., 2000; Rauchs et al., 2006). Metabolic activation elicited by delayed match-to-sample (DMS) performance was observed in the rostral PRc, restricted to a region extending $\sim 5 \mathrm{~mm}$ posteriorly from the temporal pole (Rauchs et al., 2006, their Fig. 3). Follow-up excitotoxic lesions that included the tissue in the medial bank of the rhinal sulcus (35 and medial 36) that showed PET activation also resulted in a significant impairment in recognition memory. Similarly, Davachi and Goldman-Rakic (2001), using 2-deoxyglucose mapping in monkeys performing visual tasks, found two distinct patches of metabolic activity within the rostral half of the PRc, one in the fundus of the rhinal sulcus and the other in the lateral bank of the 
PRc. Whereas the metabolic activity in the fundus was present across tasks (DMS, delayed spatial alternation, delayed object alternation, and delayed response), activity in the lateral PRc was found only during the DMS task that was performed with a $12 \mathrm{~s}$ delay. The area of metabolic activity within the fundus was likely included in our medial PRc infusions, although our injections included more extensive area within the medial bank of the rhinal sulcus. Our findings are thus consistent with the critical involvement of the area with high metabolic activity within the fundus of the PRc, as blocking glutamate transmission within this area significantly impairs object recognition memory. However, in contrast to the study by Davachi and Goldman-Rakic (2001), we found that blocking glutamate transmission within the lateral PRc, which also included a patch of high metabolic activity, was not sufficient to impair recognition memory. One possible explanation for this difference is that the metabolic activity was associated with performance on short (i.e., $12 \mathrm{~s}$ ) delays. In the present study (and in prior lesion studies), impairment is not observed at short delays. Thus, it is possible that metabolic activity in the lateral PRc did not reflect mnemonic aspects of the DNMS task.

Methodologically, there are also some key differences between the present study and prior lesion studies. In some of the lesion studies referenced above, monkeys learned the DNMS rule preoperatively using short delays and were postoperatively retrained to criterion ( $90 \%$ correct) and then, for the first time, tested on longer delays. In other lesion studies, all training took place postoperatively. Thus, in the prior studies, memory assessment was confounded by new learning. In the present study, the monkeys were pretrained on all delays and maintained performance at the criterion level throughout the study. In addition, delays were intermixed within each session, making all sessions comparable. This paradigm avoids any confounds associated with learning/relearning.

In addition to examining site specificity within perirhinal cortex using nonspecific blockade of ionotropic glutamate receptors, we also evaluated the role of AMPA receptor- and NMDA receptor-mediated synaptic transmission. In rats, AMPA receptor blockade within perirhinal cortex impaired encoding, consolidation, and retrieval of object recognition memory both at short and long delays (Winters and Bussey, 2005a). In contrast, NMDA receptor blockade within the rat perirhinal cortex impaired encoding/consolidation of memory on trials with long delays (Abe et al., 2004; Winters and Bussey, 2005a), but was without effect on retrieval. Here, we found that both NMDA and AMPA receptors were critical for normal object recognition memory. Because of the design of the task in the present study (i.e., pretreatment before a session), we were unable to separately evaluate the role of these receptor subtypes in encoding/consolidation and retrieval. Because NBQX and AP-7 display binding affinities for NMDA and AMPA receptors that are several orders of magnitude lower than that of KYNA, a direct comparison between KYNA effects and those evoked by AP-7 or NBQX is impossible without a detailed dose-response curve for each of the three drugs. Without such data it is also difficult to interpret the lack of delay dependence seen after treatment with NBQX or AP-7. Obtaining doseresponse curves to address these questions would have required a large additional number of infusions potentially leading to permanent damage to PRc, and therefore was beyond the scope of the present study. Despite this limitation, our data suggest, that like in the rodent, both NMDA- and AMPA-mediated transmission contributes to object recognition memory. On the other hand, the lack of delay dependence seen with NBQX and AP-7 can also be interpreted as a general impairment in object perception. We, however, find this explanation somewhat unlikely, as even lesions to rhinal cortex only impair object perception in cases of high feature ambiguity (Bussey et al., 2002, 2003).

The present study expands upon several decades of perirhinal lesion experiments in the nonhuman primate to identify a critical subregion within this structure for object recognition memory. Together with the studies of Tang et al. (1997) and Wu et al. (2012), which demonstrated a critical role for cholinergic neuromodulation in primate perirhinal cortex, our study clarifies the role of neurotransmitter systems that mediate object recognition memory. Blockade of AMPA, NMDA, or both AMPA and NMDA receptors together, located within the anteromedial portion of perirhinal cortex, induced significant deficits in object recognition memory. Finally, our study strongly suggests that compensation after lesions cannot explain the better than chance performance of animals on the DNMS task, as even with large zones of inactivation, our animals also performed above chance.

\section{References}

Abe H, Ishida Y, Iwasaki T (2004) Perirhinal N-methyl-D-aspartate and muscarinic systems participate in object recognition in rats. Neurosci Lett 356:191-194. CrossRef Medline

Abe H, Ishida Y, Nonaka H, Iwasaki T (2009) Functional difference between rat perirhinal cortex and hippocampus in object and place discrimination tasks. Behav Brain Res 197:388-397. CrossRef Medline

Albasser MM, Davies M, Futter JE, Aggleton JP (2009) Magnitude of the object recognition deficit associated with perirhinal cortex damage in rats: effects of varying the lesion extent and the duration of the sample period. Behav Neurosci 123:115-124. CrossRef Medline

Baxter MG, Murray EA (2001) Impairments in visual discrimination learning and recognition memory produced by neurotoxic lesions of rhinal cortex in rhesus monkeys. Eur J Neurosci 13:1228-1238. CrossRef Medline

Bellgowan PS, Buffalo EA, Bodurka J, Martin A (2009) Lateralized spatial and object memory encoding in entorhinal and perirhinal cortices. Learn Mem 16:433-438. CrossRef Medline

Blaizot X, Landeau B, Baron JC, Chavoix C (2000) Mapping the visual recognition memory network with PET in the behaving baboon. J Cereb Blood Flow Metab 20:213-219. CrossRef Medline

Buffalo EA, Ramus SJ, Clark RE, Teng E, Squire LR, Zola SM (1999) Dissociation between the effects of damage to perirhinal cortex and area TE. Learn Mem 6:572-599. CrossRef Medline

Buffalo EA, Ramus SJ, Squire LR, Zola SM (2000) Perception and recognition memory in monkeys following lesions of area TE and perirhinal cortex. Learn Mem 7:375-382. CrossRef Medline

Buffalo EA, Bellgowan PS, Martin A (2006) Distinct roles for medial temporal lobe structures in memory for objects and their locations. Learn Mem 13:638-643. CrossRef Medline

Bunce JG, Barbas H (2011) Prefrontal pathways target excitatory and inhibitory systems in memory-related medial temporal cortices. Neuroimage 55:1461-1474. CrossRef Medline

Bunce JG, Zikopoulos B, Feinberg M, Barbas H (2013) Parallel prefrontal pathways reach distinct excitatory and inhibitory systems in memoryrelated rhinal cortices. J Comp Neurol 521:4260-4283. CrossRef Medline

Bussey TJ, Duck J, Muir JL, Aggleton JP (2000) Distinct patterns of behavioural impairments resulting from fornix transection or neurotoxic lesions of the perirhinal and postrhinal cortices in the rat. Behav Brain Res 111:187-202. CrossRef Medline

Bussey TJ, Saksida LM, Murray EA (2002) Perirhinal cortex resolves feature ambiguity in complex visual discriminations. Eur J Neurosci 15:365-374. CrossRef Medline

Bussey TJ, Saksida LM, Murray EA (2003) Impairments in visual discrimination after perirhinal cortex lesions: testing "declarative" vs "perceptualmnemonic" views of perirhinal cortex function. Eur J Neurosci 17:649-660. CrossRef Medline

Davachi L, Goldman-Rakic PS (2001) Primate rhinal cortex participates in both visual recognition and working memory tasks: functional mapping with 2-DG. J Neurophysiol 85:2590-2601. Medline

DesJardin JT, Holmes AL, Forcelli PA, Cole CE, Gale JT, Wellman LL, Gale K, Malkova L (2013) Defense-like behaviors evoked by pharmacological disinhibition of the superior colliculus in the primate. J Neurosci 33:150155. CrossRef Medline 
Dybdal D, Forcelli PA, Dubach M, Oppedisano M, Holmes A, Malkova L, Gale K (2013) Topography of dyskinesias and torticollis evoked by inhibition of substantia nigra pars reticulata. Mov Disord 28:460-468. CrossRef Medline

Forcelli PA, Palchik G, Leath T, DesJardin JT, Gale K, Malkova L (2014) Memory loss in a nonnavigational spatial task after hippocampal inactivation in monkeys. Proc Natl Acad Sci U S A 111:4315-4320. CrossRef Medline

Fox AS, Shelton SE, Oakes TR, Converse AK, Davidson RJ, Kalin NH (2010) Orbitofrontal cortex lesions alter anxiety-related activity in the primate bed nucleus of stria terminalis. J Neurosci 30:7023-7027. CrossRef Medline

Friedman DP, Murray EA, O’Neill JB, Mishkin M (1986) Cortical connections of the somatosensory fields of the lateral sulcus of macaques: evidence for a corticolimbic pathway for touch. J Comp Neurol 252:323-347. CrossRef Medline

Goulet S, Murray EA (2001) Neural substrates of crossmodal association memory in monkeys: the amygdala versus the anterior rhinal cortex. Behav Neurosci 115:271-284. CrossRef Medline

Holmes AL, Forcelli PA, DesJardin JT, Decker AL, Teferra M, West EA, Malkova L, Gale K (2012) Superior colliculus mediates cervical dystonia evoked by inhibition of the substantia nigra pars reticulata. J Neurosci 32:13326-13332. CrossRef Medline

Kondo H, Saleem KS, Price JL (2005) Differential connections of the perirhinal and parahippocampal cortex with the orbital and medial prefrontal networks in macaque monkeys. J Comp Neurol 493:479-509. CrossRef Medline

Kowalska DM, Bachevalier J, Mishkin M (1991) The role of the inferior prefrontal convexity in performance of delayed nonmatching-to-sample. Neuropsychologia 29:583-600. CrossRef Medline

Lavenex P, Suzuki WA, Amaral DG (2002) Perirhinal and parahippocampal cortices of the macaque monkey: projections to the neocortex. J Comp Neurol 447:394-420. CrossRef Medline

Lavenex P, Suzuki WA, Amaral DG (2004) Perirhinal and parahippocampal cortices of the macaque monkey: intrinsic projections and interconnections. J Comp Neurol 472:371-394. CrossRef Medline

Li L, Miller EK, Desimone R (1993) The representation of stimulus familiarity in anterior inferior temporal cortex. J Neurophysiol 69:1918-1929. Medline

Málková L, Bachevalier J, Webster M, Mishkin M (2000) Effects of neonatal inferior prefrontal and medial temporal lesions on learning the rule for delayed nonmatching-to-sample. Dev Neuropsychol 18:399-421. CrossRef Medline

Málková L, Bachevalier J, Mishkin M, Saunders RC (2001) Neurotoxic lesions of perirhinal cortex impair visual recognition memory in rhesus monkeys. Neuroreport 12:1913-1917. CrossRef Medline

Malkova L, Alvarado MC, Bachevalier J (2014) Effects of separate or combined neonatal damage to the orbital frontal cortex and the inferior convexity on object recognition in monkeys. Cereb Cortex. Advance online publication. Retrieved Sept. 26, 2014. doi: 10.1093/cercor/bhu227.

Mesulam MM, Mufson EJ (1982) Insula of the old world monkey. III: efferent cortical output and comments on function. J Comp Neurol 212:38-52. CrossRef Medline

Meunier M, Bachevalier J, Mishkin M, Murray EA (1993) Effects on visual recognition of combined and separate ablations of the entorhinal and perirhinal cortex in rhesus monkeys. J Neurosci 13:5418-5432. Medline

Meunier M, Bachevalier J, Mishkin M (1997) Effects of orbital frontal and anterior cingulate lesions on object and spatial memory in rhesus monkeys. Neuropsychologia 35:999-1015. CrossRef Medline

Miller EK, Li L, Desimone R (1991) A neural mechanism for working and recognition memory in inferior temporal cortex. Science 254:1377-1379. CrossRef Medline

Miyamoto K, Adachi Y, Osada T, Watanabe T, Kimura HM, Setsuie R, Miyashita Y (2014) Dissociable memory traces within the macaque medial temporal lobe predict subsequent recognition performance. J Neurosci 34:1988-1997. CrossRef Medline

Murray EA, Gaffan EA, Flint RW Jr (1996) Anterior rhinal cortex and amygdala: dissociation of their contributions to memory and food preference in rhesus monkeys. Behav Neurosci 110:30-42. CrossRef Medline
National Research Council (2011) Guide for the care and use of laboratory animals, Ed 8. Washington, D.C: National Academies.

O'Reilly JX, Croxson PL, Jbabdi S, Sallet J, Noonan MP, Mars RB, Browning PG, Wilson CR, Mitchell AS, Miller KL, Rushworth MF, Baxter MG (2013) Causal effect of disconnection lesions on interhemispheric functional connectivity in rhesus monkeys. Proc Natl Acad Sci U S A 110: 13982-13987. CrossRef Medline

Rauchs G, Blaizot X, Giffard C, Baron JC, Insausti R, Chavoix C (2006) Imaging visual recognition memory network by PET in the baboon: perirhinal cortex heterogeneity and plasticity after perirhinal lesion. J Cereb Blood Flow Metab 26:301-309. CrossRef Medline

Saleem KS, Price JL, Hashikawa T (2007) Cytoarchitectonic and chemoarchitectonic subdivisions of the perirhinal and parahippocampal cortices in macaque monkeys. J Comp Neurol 500:973-1006. CrossRef Medline

Suzuki WA, Amaral DG (1994) Topographic organization of the reciprocal connections between the monkey entorhinal cortex and the perirhinal and parahippocampal cortices. J Neurosci 14:1856-1877. Medline

Suzuki WA, Amaral DG (2003) Perirhinal and parahippocampal cortices of the macaque monkey: cytoarchitectonic and chemoarchitectonic organization. J Comp Neurol 463:67-91. CrossRef Medline

Suzuki WA, Zola-Morgan S, Squire LR, Amaral DG (1993) Lesions of the perirhinal and parahippocampal cortices in the monkey produce longlasting memory impairment in the visual and tactual modalities. J Neurosci 13:2430-2451. Medline

Tang Y, Mishkin M, Aigner TG (1997) Effects of muscarinic blockade in perirhinal cortex during visual recognition. Proc Natl Acad Sci U S A 94:12667-12669. CrossRef Medline

Van Hoesen G, Pandya DN, Butters N (1975) Some connections of the entorhinal (area 28) and perirhinal (area 35) cortices of the rhesus monkey. II. Frontal lobe afferents. Brain Res 95:25-38. CrossRef Medline

von Bonin G, Bailey P (1947) The neocortex of Macaca mulatta. University of Illinois.

Warburton EC, Barker GR, Brown MW (2013) Investigations into the involvement of NMDA mechanisms in recognition memory. Neuropharmacology 74:41-47. CrossRef Medline

Webster MJ, Ungerleider LG, Bachevalier J (1995) Development and plasticity of the neural circuitry underlying visual recognition memory. Can J Physiol Pharmacol 73:1364-1371. CrossRef Medline

Wellman LL, Gale K, Malkova L (2005) GABAA-mediated inhibition of basolateral amygdala blocks reward devaluation in macaques. J Neurosci 25:4577-4586. CrossRef Medline

West EA, DesJardin JT, Gale K, Malkova L (2011) Transient inactivation of orbitofrontal cortex blocks reinforcer devaluation in macaques. J Neurosci 31:15128-15135. CrossRef Medline

Wilke M, Turchi J, Smith K, Mishkin M, Leopold DA (2010) Pulvinar inactivation disrupts selection of movement plans. J Neurosci 30:8650-8659. CrossRef Medline

Winters BD, Bussey TJ (2005a) Glutamate receptors in perirhinal cortex mediate encoding, retrieval, and consolidation of object recognition memory. J Neurosci 25:4243-4251. CrossRef Medline

Winters BD, Bussey TJ (2005b) Transient inactivation of perirhinal cortex disrupts encoding, retrieval, and consolidation of object recognition memory. J Neurosci 25:52-61. CrossRef Medline

Winters BD, Forwood SE, Cowell RA, Saksida LM, Bussey TJ (2004) Double dissociation between the effects of peri-postrhinal cortex and hippocampal lesions on tests of object recognition and spatial memory: heterogeneity of function within the temporal lobe. J Neurosci 24:5901-5908. CrossRef Medline

Wu W, Saunders RC, Mishkin M, Turchi J (2012) Differential effects of m1 and $\mathrm{m} 2$ receptor antagonists in perirhinal cortex on visual recognition memory in monkeys. Neurobiol Learn Mem 98:41-46. CrossRef Medline

Zola-Morgan S, Squire LR, Amaral DG, Suzuki WA (1989) Lesions of perirhinal and parahippocampal cortex that spare the amygdala and hippocampal formation produce severe memory impairment. J Neurosci 9:4355-4370. Medline 